\title{
Isoxanthohumol exerts anticancer activity against drug- resistant thyroid cancer cells by inhibiting cell migration and invasion, apoptosis induction and targeting $\mathrm{PI} 3 \mathrm{~K} / \mathrm{AKT} / \mathrm{m}-\mathrm{TOR}$ signaling pathway
}

\author{
Xiliang Zhang, Xiaodong Yang, Zhen Cao, Zhanwei Zhao, Yuxing Zhang* \\ Department of General Surgery, The Sixth Medical Center of PLA General Hospital, Beijing 100048, China \\ *For correspondence: Email: doctor_zyx1984@163.com; Tel/Fax: 0086-010-66958114 \\ Sent for review: 20 October 2020 \\ Revised accepted: 22 May 2021
}

\begin{abstract}
Purpose: To investigate the anticancer effect of isoxanthohumol against drug-resistant thyroid cancer cells. Its effect on cellular PIJK/AKT/m-TOR signaling pathway, cell migration and invasion and apoptosis were also analyzed.

Methods: The cytotoxicity of isoxanthohumol drug was examined by MTT assay. Cellular morphology was assessed by phase contrast microscopy. Fluorescence microscopy and western blotting were used to evaluate its effect on cellular apoptosis. Further, western blotting was used to monitor the levels of expression of proteins linked to PI3K/AKT/m-TOR signaling pathway.

Results: Isoxanthohumol significantly $(p<0.05)$ inhibited the proliferation and progression of drugresistant human papillary BCPAP cancer cells in a concentration- and time-dependent manner. Further, morphological assessment of BCPAP cells indicate that there were proapoptotic alterations after isoxanthohumol treatment. The results for apoptosis in BCPAP cells showed enhanced number of apoptotic cells, elevated levels of proapoptotic proteins (including Bax), and increased level of expressions of caspase-3 and caspase-9. Isoxanthohumol targeted metastatic features of BCPAP cells by inhibiting both cell migration and cell invasion in a concentration-dependent manner. Western blotting revealed remarkable inhibition of PIJK/AKT/m-TOR signalling pathway through blocking of expression of its allied proteins.

Conclusion: Isoxanthohumol exhibits potent anticancer effect in human papillary cancer cells by inducing apoptosis, inhibition of cell migration, as well as invasion and targeting PI3K/AKT/m-TOR signalling pathway. These findings could play a significant role in drug design and discovery for thyroid cancer. However, more conformational investigations are required.
\end{abstract}

Keywords: Thyroid cancer, Drug resistance, Flavonoids, Isoxanthohumol, Apoptosis

This is an Open Access article that uses a fund-ing model which does not charge readers or their institutions for access and distributed under the terms of the Creative Commons Attribution License (http://creativecommons.org/licenses/by/4.0) and the Budapest Open Access Initiative (http://www.budapestopenaccessinitiative.org/read), which permit unrestricted use, distribution, and reproduction in any medium, provided the original work is properly credited.

Tropical Journal of Pharmaceutical Research is indexed by Science Citation Index (SciSearch), Scopus, International Pharmaceutical Abstract, Chemical Abstracts, Embase, Index Copernicus, EBSCO, African Index Medicus, JournalSeek, Journal Citation Reports/Science Edition, Directory of Open Access Journals (DOAJ), African Journal Online, Bioline International, Open-J-Gate and Pharmacy Abstracts

\section{INTRODUCTION}

Global cancer burden is increasing at an alarming rate due to a number of factors including aging, population growth and some alterations in risks linked to economic and social development. The countries with fast emerging economies have witnessed a shift in poverty 
allied cancers and infections to cancers, mainly attributed to adopted lifestyle of representative industrialized countries. The year of 2018 recorded nearly 10 million cancer deaths and above 18 million new cancer cases [1]. Meanwhile, thyroid cancer occurrences are increasing at a rapid pace and almost fastest among all cancer malignancies.

Despite a 2.4-fold increase in the number of thyroid cancer incidences from 1973-2002, the associated mortality rate remained stable [2]. This distressing enhancement in thyroid cancer occurrence is mostly attributed to its primary detection using ultrasound and ultrasoundguided fine needle for investigation of cytology. The exposure to ionizing radiation is only one established major risk factor contributing to thyroid cancer development by epidemiological studies of the disease [3]. Thyroid cancer treatment varies according to tumor stage and type. The currently available treatment approaches include primary radioactive iodine treatment, surgery, TSH suppression therapy and chemotherapy [4]. However, the disease relapse within 3 years of primary treatment remains a big hurdle in thyroid cancer treatment even if the mortality rate is under control.

Potential therapeutics have been isolated from plant based natural products and these products serve as a pool of unknown and unexplored chemical entities that can assist to address current global health issues [5,6]. Flavonoids are a large class of phytochemicals with more than 4,000 known members. They possess diverse structural varieties like flavones, flavonols, flavanones, flavanonols and isoflavones [9-10]. These compounds have been found biologically and medicinally important. They show antianalgesic, hypolipidemic, hypocholesterolemic, anti-inflammatory, antihypertensive, antiestrogenic and anticancer activities [11]. Isoxanthohumol is an isomeric form of xanthohumol flavanones and it is found in large abundance beer. Likewise its isomeric form isoxanthohumol shows remarkable bioactivities including anticancer activity. It has been reported to induce apoptosis, oxidative stress, reduces mitochondrial membrane potential and adipogenesis [12]. Therefore, this study was designed to explore the anticancer activity of isoxanthohumol against drug-resistant thyroid cancer along with assessing its effects on $\mathrm{PI}$ KK/AKT/m-TOR signalling pathway, cell migration and invasion and apoptosis.

\section{EXPERIMENTAL}

\section{Assessment of cellular proliferation}

MTT viability test was used to analyze the viability of drug-resistant human papillary BCPAP thyroid cancer cells after treatment with isoxanthohumol. In brief, 10, 000 cells/well were cultured 96-well plate for $24 \mathrm{~h}$. Preculturing of BCPAP cells was followed by isoxanthohumol treatment $(0,12,24,48$ and $96 \mu \mathrm{M}$ for $24 \mathrm{~h})$ by incubation in $5 \% \mathrm{CO}_{2}$ and $95 \%$ humidified air at $37^{\circ} \mathrm{C}$. Post drug exposure cells were washed with phosphate buffered saline. Thereafter, to each well was added MTT stock solution and incubated for $4 \mathrm{~h}$. MTT solution generates formazan crystals with viable cells and those crystals were dissolved with dimethyl sulphoxide for colorimetric assessment. Reading of the optical density was carried out at $490 \mathrm{~nm}$ with an ELISA reader (Molecular Devices, Sunnyvale, CA, United States).

\section{Phase contrast microscopy}

Morphological assessment of isoxanthohumol treated human papillary BCPAP thyroid cancer cells was carried via phase contrast microscopy. Briefly, $2.5 \times 10^{5}$ BCPAP cells were plated in 12well plates and incubated overnight at $37^{\circ} \mathrm{C}$. After incubation BCPAP cells were subjected to isoxanthohumol treatment at varying concentrations $(0,12,48$ and $96 \mu \mathrm{M})$ for $48 \mathrm{~h}$. Afterwards, DMEM was removed and isoxanthohumol treated BCPAP cells were washed with phosphate buffered saline. Finally, morphological assessments were performed under a phase contrast microscope (Leica DMI 3000B, Germany).

\section{Fluorescence microscopy}

Human papillary BCPAP thyroid cancer cells were harvested at $70-80 \%$ of confluence and then seeded on 24-well plates. Afterwards, cells were trypsinized using trypsin over coverslips placed in 24-well plates post treatment with various isoxanthohumol concentrations $(0,12,48$ and $96 \mu \mathrm{M})$ for $48 \mathrm{~h}$. Thereafter, fixation of the treated cells was performed using formaldehyde (4\%) followed by $10 \mu \mathrm{L}$ of AO/EB staining solution for 3-4 minutes. Cells were finally analyzed under fluorescence microscope (Olympus Co., Tokyo, BX51TRF, Japan) for apoptosis analysis. 


\section{Transwell invasion and migration assays}

The effect of isoxanthohumol on cell invasion and migration was analyzed by transwell chambers coated with Matrigel. Target cells were suspended within $2 \%$ FBS containing DMEM and various concentrations of isoxanthohumol $(0$, 12,48 and $96 \mu \mathrm{M}$ ) for $48 \mathrm{~h}$, which was then, loaded onto the upper transwell chambers. These chambers were fitted with membranes of $8 \mu \mathrm{m}$ pore size. The lower chambers contained FBS $(10 \%)$ in addition to DMEM but deprived of target cells. All transwell chambers were incubated for $24 \mathrm{~h}$ at $37^{\circ} \mathrm{C}$ followed by removal of upper membranes and lower transwell chambers bearing invasive cells which were fixed in ethanol. Post fixation, fixed invasive cells were stained with Giemsa staining solution and numbered under a light microscope.

\section{Western blotting}

BCPAP cells were cultured in 24-well plates bearing $2.5 \times 10^{4}$ cells in each well and harvested after $90 \%$ of growth confluence. Afterwards, BCPAP cells were treated with isoxanthohumol drug at various concentrations $(0,12,48$ and $96 \mu \mathrm{M})$ for $48 \mathrm{~h}$. The treated cells were then lysed using lysis buffer and the proteins within each lysate was measured by bicinchoninic acid assay. Equal amounts of 45 $\mu \mathrm{g}$ proteins were loaded in SDS-PAGE (10 \%) followed by transfer to polyvinylidene difluoride membranes electrophoretically. These membranes were blocked with skimmed milk (5 $\%$ ) in TBST followed by incubation with 1:1, 000 dilutions of primary antibodies (anti-Bax, anti-Bcl2, anti-Bcl-XL) (Cell Signaling Technology, Inc., Danvers, MA, United States)) overnight at $4{ }^{\circ} \mathrm{C}$. Thereafter, incubation with horseradish peroxidase conjugated secondary antibodies (Cell Signaling Technology, Inc., Danvers, MA, United States) was performed for $2 \mathrm{~h}$ at $25 \pm$ $1^{\circ} \mathrm{C}$. Finally, protein signals were detected using iBright Western Blot Imaging Systems (ThermoFisher Scientific, Inc., Waltham, MA, United States).

\section{Statistical analysis}

The experiments were repeated thrice for each drug concentrations in all assays. Data was shown as mean of three experiments \pm SEM (standard error of the mean). $P<0.01$ was considered statistically significant and statistical analyses were carried via Student's Newman ttest or Keul's test.

\section{RESULTS}

\section{Isoxanthohumol induced cytotoxicity in BCPAP cells}

Flavonoids have been reported with substantial cytotoxic effects against several human cancer cell lines both in vitro and in vivo. Herein, the cytotoxic effects of isoxanthohumol were estimated via MTT assay. Isoxanthohumol (Figure 1) was employed at different concentrations $(0,12,24,48$ and $96 \mu \mathrm{M}$ for $24 \mathrm{~h})$ against BCPAP cells and cell viability was determined using colorimetric analysis. The results revealed that isoxanthohumol induced remarkable cytotoxicity in BCPAP cells in concentration as well as time-dependent manner. Considering control cells as $100 \%$ viable, the viability was reduced to $20 \%$ at $96 \mu \mathrm{M}$ (Figure 2).

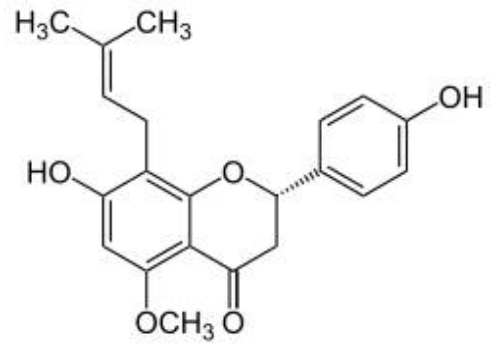

Figure 1: Chemical structure of isoxanthohumol molecule

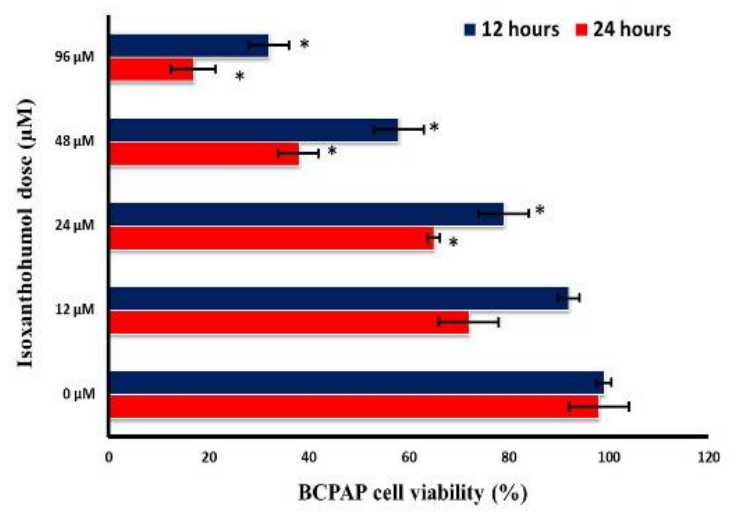

Figure 2: Effect of isoxanthohumol on drug-resistant human papillary BCPAP thyroid cancer cells. BCPAP cells were treated with the indicated concentrations of isoxanthohumol for the indicated time intervals. The figure shows reduced viability of BCPAP cells on isoxanthohumol exposure in comparison to the control group. The experiments were repeated thrice. Data was shown as mean of three experiments \pm SEM (standard error of the mean). $P<0.01$ was considered as statistically significant 
Isoxanthohumol disturbed normal morphology of BCPAP cells

Normal morphology of cell membrane, cell organelles and nucleus maintain the integrity of cells. Changes, if any, induced in normal morphology of isoxanthohumol treated BCPAP cells were assessed through phase contrast microscopy. Results indicated that isoxanthohumol brought about significant morphological modifications which indicate that antiproliferative effects of isoxanthohumol could be mediated via alterations in cell morphology. Isoxanthohumol disturbed the normal morphology of plasma membranes, caused membrane blebbing and nuclear disintegration (Figure 3).

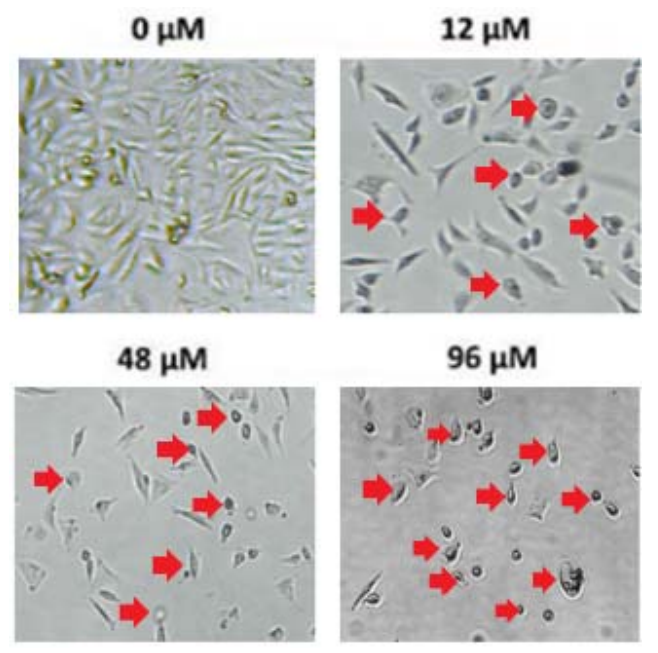

Figure 3: Morphological assessment of BCPAP cells after being exposed to indicated concentrations of isoxanthohumol. The figure depicts remarkable morphological modifications indicating cell death of these target cells. Arrows point towards the structural deformity induced by isoxanthohumol like membrane blebbing, rupture, disintegration, circular cells and loss in density. The experiments were repeated thrice. Data was shown as mean of three experiments

\section{Isoxanthohumol induced apoptosis in BCPAP cells}

Apoptosis is one of the leading and potential targets often selected by chemopreventive drugs. It is a natural process activated under stressful conditions and injury. BCPAP cells were treated with different isoxanthohumol concentration $(0$, 12,48 and $96 \mu \mathrm{M}$ ) for $24 \mathrm{~h}$ and apoptotic investigations were carried out via fluorescence microscopy. Results showed that isoxanthohumol potentially stimulated apoptosis in BCPAP cells. Yellow-green (early apoptotic), orange-red (late apoptotic) and red (necrotic cells) fluorescence indicate different stage apoptotic cells (Figure 4). The fact that apoptosis was induced by isoxanthohumol in BCPAP cells was further supported by western blotting assay. Results showed enhancement in proapoptotic (Bax and caspases) protein levels and reduction in the anti-apoptotic (Bcl-2 and $\mathrm{Bcl}-\mathrm{XL}$ ) protein levels (Figure 5). Therefore, it may be concluded that antiproliferative property of isoxanthohumol against BCPAP cells was due its apoptosis stimulation propensity.
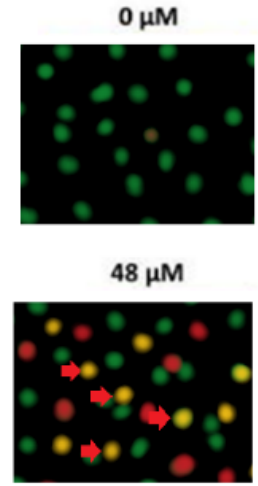

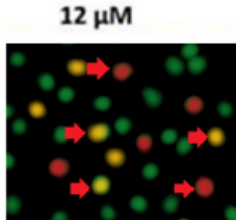

$96 \mu \mathrm{M}$

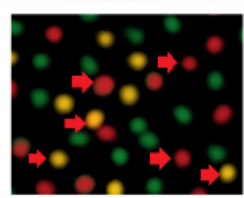

Figure 4: Apoptosis-allied antiproliferative effect of isoxanthohumol. After treatment of BCPAP cells with the indicated concentrations of test drug, $A O / E B$ staining was performed. The arrows point at early apoptotic (yellow-green), late apoptotic (orange red) and necrotic (red) BCPAP cells in isoxanthohumol treated group and in case of control group no such fluorescence was observed

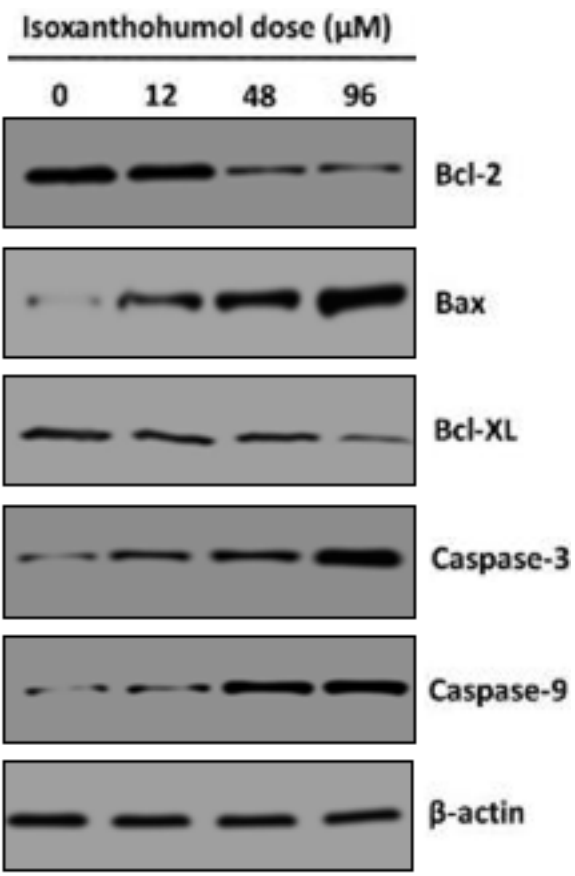

Figure 5: Enhanced expressions of proapoptotic proteins and decreased expressions of anti-apoptotic proteins. Each individual experiment was executed in triplicates. $\beta$-Actin was used as normalization control 
Isoxanthohumol targeted cell migration and invasion of BCPAP cells

We all know cancer is a dangerous malignancy, but it is more dangerous when exists in metastatic form which often leads to poor diagnosis and complicates chemotherapy. Herein, isoxanthohumol was investigated for its anti-metastatic effect against BCPAP cells. After exposure to different isoxanthohumol concentrations $(0,12,48$ and $96 \mu \mathrm{M})$ cells were analyzed for invasion and migration via transwell chambers invasion and migration assay. Isoxanthohumol was observed to remarkably reduce the number of invasive BCPAP cells in a concentration-dependent manner (Figure 6). It was also observed that the number of migrated BCPAP cells reduced on isoxanthohumol treatment and upon increasing its concentrations (Figure 7). Therefore, it may be concluded that isoxanthohumol could inhibit the metastatic nature of the human thyroid cancer cells by inhibiting cell invasion and migration.
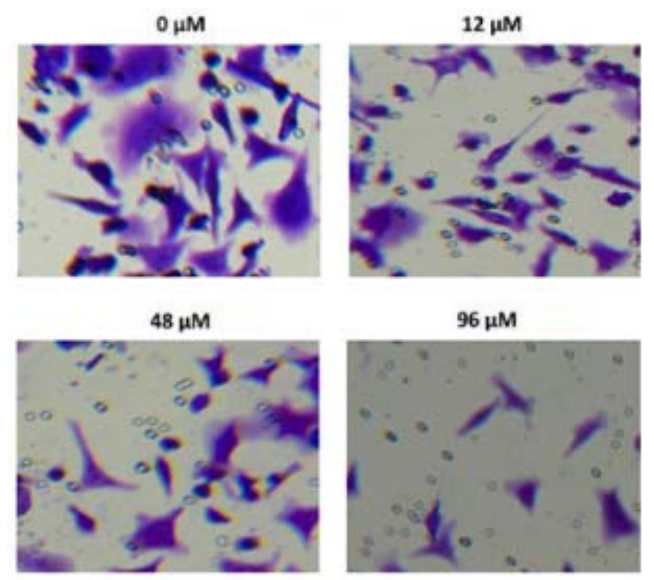

Figure 6: BCPAP cell invasion after exposure to isoxanthohumol at indicated concentrations. The molecule led to decreased cell invasion in a concentration -dependent manner. Each individual experiment was repeated in triplicates

\section{Isoxanthohumol inhibited PI3K/AKT/m-TOR} signalling pathway in BCPAP cells

The PI3K/AKT/m-TOR signalling pathway has been reported to play a key role in a number of survival processes of a cell. This pathway hence serves as a leading target for chemopreventive drugs. Isoxanthohumol was investigated for its effects on PI3K/AKT/m-TOR signalling pathway through western blotting assay. Results showed that the expression levels of phosphorylated $\mathrm{PI} 3 \mathrm{~K}, \mathrm{AKT}$ and $\mathrm{m}$-TOR reduced remarkably on isoxanthohumol drug exposure, in comparison to controls (Figure 8). The expression levels of
PI3K, AKT and m-TOR remained almost intact. Therefore, it may be concluded that isoxanthohumol inhibited the progression of $\mathrm{PI} 3 \mathrm{~K} / \mathrm{AKT} / \mathrm{m}-\mathrm{TOR}$ signalling pathway.
$0 \mu \mathrm{M}$

$48 \mu \mathrm{M}$

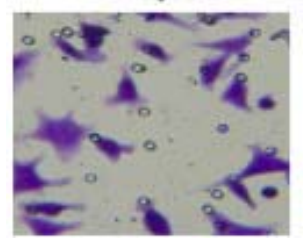

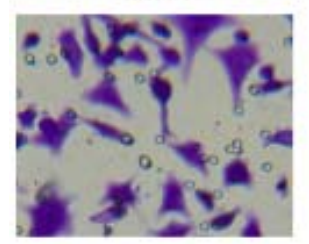

$12 \mu \mathrm{M}$

$96 \mu \mathrm{M}$

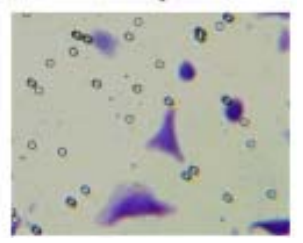

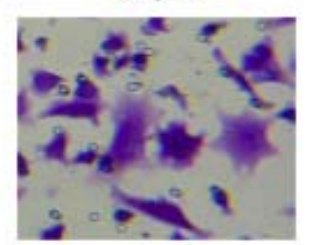

Figure 7: BCPAP cell migration after exposure to isoxanthohumol at indicated concentrations. The figure shows reduced migrated cells after test drug exposure in comparison to the control group. Each individual experiment was repeated in triplicate

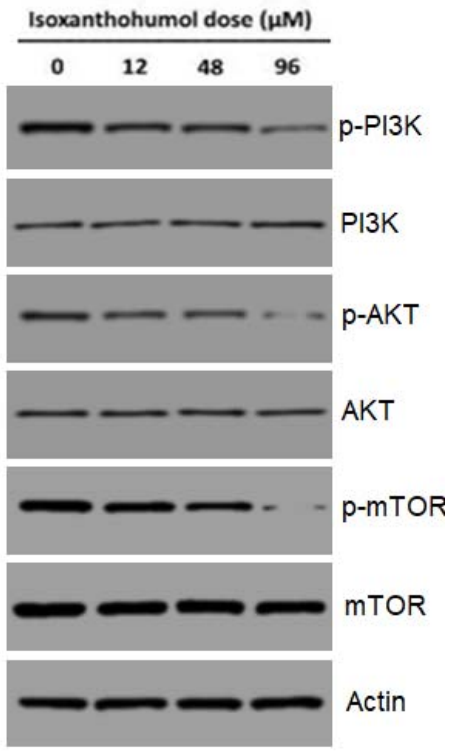

Figure 8: Effect of isoxanthohumol on $\mathrm{PI} 3 \mathrm{~K} / \mathrm{AKT} / \mathrm{m}$ TOR signalling pathway proteins. The figure shows that the expression levels of phosphorylated PI3K, AKT and m-TOR reduced remarkably on isoxanthohumol exposure. Each individual experiment was repeated in triplicates. $\beta$-Actin was used as normalization control

\section{DISCUSSION}

Thyroid cancer cases increased rapidly in the past 2-3 decades despite being associated with low mortality [13]. Till date, different histological 
sub-types of thyroid cancer have been identified including follicular, papillary, and weakly differentiated cancers (medullary and anaplastic) [14]. Thyroid cancer acquires resistance to applied therapeutic methods such as low intake of radioactive iodine from blood in radioactive iodine therapy [15]. Several genetic mutations have been linked to decreased iodine uptake of tumorous thyroid cells most importantly BARF (gene encoding B-Raf protein) mutations [16].

Acquired resistance, disease relapse and scarcity of efficient therapeutic drugs create a need of novel chemopreventives. Therefore, this research is aimed at exploring the anti-thyroid cancer potency of isoxanthohumol. The effects of the test drug on PI3K/AKT/m-TOR signalling pathway, cell migration and invasion and apoptosis against BCPAP thyroid cancer cells was also determined. It was observed that isoxanthohumol was cytotoxic in tumorous BCPAP cells. This cytotoxicity was estimated with MTT assay which revealed its concentrationand time-dependence. Afterwards, an attempt was made to search for the mechanism underlying the antiproliferative potency of isoxanthohumol in BCPAP cells.

Previously, isoxanthohumol had been reported to induce proapoptotic effects in adipocytes (3T3L1) [12]. Apoptosis is a highly regulated and conserved mechanism in multicellular organisms and mammals. It is controlled by different intrinsic and extrinsic signals. Apoptosis in a normal cell remains dormant and operates in case of aging, malfunctioning and damage [17]. Herein, isoxanthohumol was reported to have proapoptotic effects against tumorous BCPAP cells as well. The apoptotic cell death was supported by enhanced levels of Bax, caspase-3 and caspase-9 and downregulation of Bcl-2, Bcl$\mathrm{XL}$ protein expressions. Isoxanthohumol produced remarkable suppressive effects on migration and invasion of tumorous BCPAP cells. Therefore, isoxanthohumol significantly inhibited thyroid cancer metastasis. The PI3K/AKT/m-TOR signalling pathway regulates a number of survival functions of normal/cancerous cells [18]. It regulates cell growth, differentiation and development and in cancer cells due to uncontrolled multiplication of cells its role remains very important. For chemopreventives, the PI3K/AKT/m-TOR signalling pathway serves as a major target in a cancer cell to initiate cell death mechanism. Herein, isoxanthohumol drug remarkably targeted the expression of PI3K/AKT/m-TOR signalling pathway allied proteins in BCPAP cells thereby downregulating their expressions in concentration-dependent manner.

\section{CONCLUSION}

The results of this investigation indicate the remarkable anticancer activity of isoxanthohumol against drug-resistant thyroid cancer. The anticancer effect of isoxanthohumol is exerted by targeting $\mathrm{PI} 3 \mathrm{~K} / \mathrm{AKT} / \mathrm{m}-\mathrm{TOR}$ signalling pathway, inhibition of cell migration and invasion, and apoptosis induction. Thus, these findings indicate that isoxanthohumol is a potential lead candidate for the development of an anti-thyroid cancer drug. Further investigations are, however, required.

\section{DECLARATIONS}

\section{Conflict of interest}

No conflict of interest is associated with this work.

\section{Contribution of authors}

We declare that this work was done by the authors named in this article and all liabilities pertaining to claims relating to the content of this article will be borne by the authors.

\section{Open Access}

This is an Open Access article that uses a funding model which does not charge readers or their institutions for access and distributed under the terms of the Creative Commons Attribution License (http://creativecommons.org/licenses/by/ 4.0) and the Budapest Open Access Initiative (http://www.budapestopenaccessinitiative.org/rea d), which permit unrestricted use, distribution, and reproduction in any medium, provided the original work is properly credited.

\section{REFERENCES}

1. Bray F, Ferlay J, Soerjomataram I, Siegel RL, Torre $L A$, Jemal A. Global cancer statistics 2018: GLOBOCAN estimates of incidence and mortality worldwide for 36 cancers in 185 countries. CA Cancer Clin a cancer 2018; 68(6): 394-424.

2. Davies L, Welch HG. Increasing incidence of thyroid cancer in the United States, 1973-2002. JAMA 2006; 295(18): 2164-2167.

3. Meinhold CL, Ron E, Schonfeld SJ, Alexander BH, Freedman DM, Linet MS, Berrington de González A. Nonradiation risk factors for thyroid cancer in the US Radiologic Technologists Study. Am J Epidemiol 2010; 171(2): 242-252.

4. Cabanillas ME, McFadden DG, Durante C. Thyroid cancer. Lancet 2016; 388(10061): 2783-2795.

Trop J Pharm Res, June 2021; 20(6): 1156 
5. Ayaz M, Ullah F, Sadiq A, Kim MO, Ali T. Natural Products-Based Drugs: Potential Therapeutics against Alzheimer's Disease and other Neurological Disorders. Front Pharmacol 2019; 10: 1417.

6. Tewari $D$, Rawat $P$, Singh $P K$. Adverse drug reactions of anticancer drugs derived from natural sources. Food Chem Toxicol 2019; 123: 522-535.

7. Faggio C, Sureda A, Morabito S, Sanches-Silva A, Mocan A, Nabavi SF, Nabavi SM. Flavonoids and platelet aggregation: A brief review. Eur J Pharmacol 2017; 807: 91-101.

8. Wang $T Y, L i$ Q, Bi KS. Bioactive flavonoids in medicinal plants: Structure, activity and biological fate. Asian J Pharm Sci 2018; 13(1): 12-23.

9. George VC, Dellaire G, Rupasinghe HV. Plant flavonoids in cancer chemoprevention: role in genome stability. J Nutri Biochem 2017; 45: 1-4.

10. Russo GL, Usso M, Spagnuolo C, Moccia S. Ins and outs of flavonoids in cancer prevention vs. cancer therapy: $A$ lesson from quercetin in leukemia. Proceedings 2017; 1(10): 977.

11. Mukai R. Prenylation enhances the biological activity of dietary flavonoids by altering their bioavailability. Biosci Biotechnol Biochem 2018; 82(2): 207-215.

12. Yang JY, Della-Fera MA, Rayalam S, Baile CA. Effect of xanthohumol and isoxanthohumol on 3T3-L1 cell apoptosis and adipogenesis. Apoptosis 2007; 12(11): 1953-1963.
13. Vaccarella S, Dal Maso L, Laversanne M, Bray F, Plummer M, Franceschi S. The impact of diagnostic changes on the rise in thyroid cancer incidence: a population-based study in selected high-resource countries. Thyroid 2015; 25(10): 1127-1136.

14. Fagin JA, Wells Jr SA. Biologic and clinical perspectives on thyroid cancer. N Engl J Med 2016; 375(11): 10541067.

15. Jaber $T$, Waguespack SG, Cabanillas ME, Elbanan $M$, Vu T, Dadu R, Sherman SI, Amit M, Santos EB, Zafereo $M$, Busaidy NL. Targeted therapy in advanced thyroid cancer to resensitize tumors to radioactive iodine. J Clin Endocrinol Metab 2018; 103(10): 3698-3705.

16. Kimura $E T$, Nikiforova $M N$, Zhu Z, Knauf JA, Nikiforov $Y E$, Fagin JA. High prevalence of BRAF mutations in thyroid cancer: genetic evidence for constitutive activation of the RET/PTC-RAS-BRAF signaling pathway in papillary thyroid carcinoma. Cancer Res 2003; 63(7): 1454-1457.

17. Shirjang S, Mansoori B, Asghari S, Duijf PH, Mohammadi A, Gjerstorff M, Baradaran B. MicroRNAs in cancer cell death pathways: apoptosis and necroptosis. Free Radic Biol Med 2019; 139: 1-15.

18. Aggarwal S, John S, Sapra L, Sharma SC, Das SN. Targeted disruption of PI3K/Akt/mTOR signaling pathway, via PI3K inhibitors, promotes growth inhibitory effects in oral cancer cells. Cancer Chemother Pharmacol 2019; 83(3): 451-461. 